\title{
Variability of Yellow River Turbid Plume Detected with Satellite Remote Sensing during Water-Sediment Regulation
}

Article in Continental Shelf Research · January 2017

DOI: 10.1016/j.csr.2017.01.017

CITATIONS

5 authors, including:

\section{Tao Zou}

Chinese Academy of Sciences

8 PUBLICATIONS 6 CITATIONS

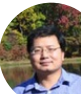

Hua Zhang

Chinese Academy of Sciences

54 PUBLICATIONS 436 CITATIONS

SEE PROFILE

SEE PROFILE 


\title{
Variability of Yellow River turbid plume detected with satellite remote sensing during water-sediment regulation
}

\author{
Kai Guo, Tao Zou, Dejuan Jiang, Cheng Tang, Hua Zhang* \\ Key Laboratory of Coastal Zone Environmental Processes and Ecological Remediation, Yantai Institute of Coastal Zone Research, Chinese Academy of Sciences, Yantai, Shandong, China
}

\section{ART ICLE INFO}

Keywords:

River plume

Remote sensing

Sediment

Yellow River

Water-Sediment Regulation

\begin{abstract}
A B S T R A C T
Water Sediment Regulations (WSRs) of the Yellow River (YR) have fundamentally altered the dynamics of freshwater and sediment transport in YR estuary and might profoundly affect water quality and ecosystem of the adjacent Bohai Sea. In this study, empirical algorithms were established to infer sea surface salinity and turbidity of YR plume using on surface reflectance products of MODIS and GOCI satellites in combination with observations from hydrographic surveys during the 2014 WSR event. Inter- and intraday variability of salinity and turbidity were quantitatively assessed and correlated with external forces including river discharge, tides, Coriolis force, and wind-driven circulation. The results revealed the enhanced offshore extension of turbid plume as WSR drastically increased freshwater and sediment discharge to river mouth. During WSR event, the area of low salinity plume ( $<25 \mathrm{psu}$ ) increased to $267 \mathrm{~km}^{2}$, while sediment plume $\left(S R_{645}>0.12 \mathrm{sr}^{-1}\right)$ occupied a maximum area of $162 \mathrm{~km}^{2}$. Intraday variation observed from geostationary GOCI data clearly illustrated the dominance of tidal current on short term dispersal pattern of freshwater and sediment plume. In comparison, wind field dominated the seasonal variation in flume transport but had insignificant impact on short term river plume dynamic during WSR. Overall, this study demonstrated that the spatial and temporal dynamic of YR plume was successfully captured by satellite remote sensing, which provided an effective tool for evaluating the environmental and ecological impact of WSRs.
\end{abstract}

\section{Introduction}

With a total of $40 \%$ global fresh water being transported from continent to ocean by the world's ten largest rivers, these rivers constitute the primary interface between terrestrial and ocean environments (Dagg et al., 2004). Coastal river plume is the major transport mechanism for fresh water, suspended sediment, dissolved carbon, nutrients, and pollutants in the estuarine and coastal waters. This river-sea interaction promotes a tandem effect on biological processes such as facilitating local fish larvae retention and fish recruitment (Grimes and Kingsford, 1996). The spatial and temporal variability of river plumes are tightly associated with environmental factors including Coriolis force, wind, river discharge, coastal currents, tidal cycles, shelf slope and submarine channel direction.

Satellite data products provide synoptic and frequent overviews of coastal water and might be the only viable approach to monitoring the dispersal of river plumes over synoptic scales (Hopkins and Lucas, 2013). The optical properties of coastal surface waters can be used to distinguish turbid plume water from ambient water masses (Lahet and Stramski, 2010). Supervised classification of ocean color data has been successfully employed to develop link between light absorption of Chromophoric Dissolved Organic Matter (CDOM) and surface salinity in Columbia River plume (Palacios et al., 2009). Four types of remote sensing data (temperature, salinity, chlorophyll, and sea level) coupled with EOF analysis has been used to identify the dispersal and movement of Congo plume (Hopkins et al., 2013). In the case of the Amazon River Basin, patterns of surface sediment distribution has been modeled based on Moderate Resolution Imaging Spectroradiometer (MODIS) data to detect the variability in main channel and observe the tributary influence on main system (Park and Latrubesse, 2014). Total suspended matter concentrations within the Adour River turbid plume has been obtained from MODIS $250 \mathrm{~m}$ imagery to describe the seasonal spatio-temporal of this plume (Petus and Marieu, 2014). It is established that the responses within ocean surface visible spectrum as a function of plume characteristic parameters (e.g. suspended sediments, salinity, CDOM, turbidity and chlorophyll-a) could enable quantitatively depict river plume variability (Long and Pavelsky, 2013; Aurin et

Corresponding author: Address: 17 Chunhui Rd, Yantai, Shandong 264003, China.

Email address: hzhang@yic.ac.cn (H. Zhang) 
al., 2013). Studies (Bowers et al., 2004; Kutser et al., 2005; Ahn et al., 2008) have confirmed the existence of a tight relationship between the ratio of reflection coefficients and CDOM absorption, particularly in the ultraviolet (UV) and blue portion of the visible spectrum. In addition, strong linear and inverse correlation between salinity and CDOM in surface water has been observed in estuaries and coastal waters around the globe. Therefore, surface reflectance properties observed from satellite remote sensing has been established as a reliable property to assess the variation of plume area and shape (Hu et al., 2004; Ahn et al., 2008; Palacios et al., 2009). However, majority of the remote sensing studies on river plumes were conducted at interannual or seasonal time scale, whereas few studies have investigated short term (inter-day or intraday) variation of plumes, which is critical for understanding the drastic change associated short-term events. The Geostationary Ocean Color Imager (GOCI) satellite launched in June 2010 provided opportunity to measure dynamic variation in semi-diurnal environments for its better temporal coverage (Choi et al., 2012).

The Yellow River (YR), the most sediment-filled and the sixth longest river on earth, carries tremendous amounts of freshwater and sediment through its plume to the semi-enclosed Bohai Sea. Field measurements and numerical simulation have been conducted to study the dynamics of YR plume. Based on the cruise observation data from 2000 to 2005, it was reported that salinity level in nearby Laizhou Bay was primarily controlled by YR plume (Zhao et al., 2010). The survey in summer 2007 demonstrated that suspended sediments concentrated in the river mouth and extended southerly driven by tidal current (Qiao et al., 2010). A 3-D baroclinic hydrodynamic model was set to simulate YR plumes and the result showed that the seasonal behavior of the plume corresponded to seasonal variation in wind field. The prominent plume extended northeastward in summer time and propagated to the southeastern corner of the Laizhou Bay in response to the strong northerly wind in winter (Wang et al., 2008). Monthly averaged surface reflectance data retrieved from MODIS demonstrated that the YR turbid plume extended seaward but had little impact on the SSC distributions in the southern Bohai Strait during the flood season (Bi et al., 2011). Suspended sediment fluxes and dispersion patterns off the past and present YR plume were studied based on the hydrographic data by Wang et al. (2007) and $\mathrm{Bi}$ et al. (2010a) respectively, and they reached an agreement that tidal shear fronts and alongshore tidal currents were the major dynamic factors controlling the sediment dispersion.

During the past decades, the annual water discharges of YR have dramatically reduced $70 \%$ compared with 1950 s due to dam construction, water consumption, and climate change (Wang et al., 2006). The unbalanced relationship between water and sediments results in an elevated riverbed over $10 \mathrm{~m}$ above the surrounding floodplain (Yu et al., 2013). Therefore in year 2002, the YR Conservancy Committee (YRCC) initialized the Water-Sediment Regulation (WSR) for improving the river ecological environment. Through the joint operation of three large reservoirs in the middle reaches of the YR, large quantities of fresh water were released on a period of two weeks when about $50 \%$ of annual sediment discharge (Bi et al., 2014) and over $20 \%$ of annual water discharge (Wang et al., 2011) took place. These flash flood scours river channel covered with huge deposits of sediment and transported them into sea. Consequently, this intensive freshwater and sediment injection in short time also caused YR plume pathway shift (Wang et al., 2005), variation of horizontal and vertical salinity distribution (Mao et al., 2008; Wang et al., 2011), and change of suspended sediment transport (Yu et al., 2013). Despite those research efforts, substantial knowledge gap on the variability and controlling mechanisms of YR plume still exists due to limited measurements and becomes an obstacle for scientific planning of the WSR scheme.

The objectives of this study are: 1) establishing empirical algorithms to infer salinity and turbidity of YR plume using surface reflectance products of MODIS and GOCI satellites in combination with in-situ data measured during the 2014 WSR cruises; 2) evaluating the inter-day and intra-day variation of YR plume using retrieved sea surface salinity (SSS) and surface turbidity; and 3) elucidating the evolution mechanisms of YR turbid plume as impacted by external forces such as river discharge, tidal current, Coriolis effect, and wind-driven circulation.

\section{Material and methods}

\subsection{Study area}

The Yellow River is one of the world's most turbid rivers and contributes $71 \%$ of total runoff freshwater inputs to Bohai Sea. Since 1960s, the annual averaged flow discharge of YR has dropped dramatically from $1900 \mathrm{~m}^{3} / \mathrm{s}$ to $320 \mathrm{~m}^{3} / \mathrm{s}$ in the 1990 s (Mao et al., 2008). Similar conditions appears on the annual sediment load, which declined sharply from $1.33 \mathrm{Gt}$ in 1960 s to $0.15 \mathrm{Gt}$ after 2000 (Bi et al., 2014). The river mouth also altered position from abandoned Qingshuigou river mouth in 1996 to the present northeastward to Bohai Sea (Fig. 1). The tide of YR estuary is irregular semi-diurnal with an average tidal range of $0.6-0.8 \mathrm{~m}$ at river mouth and rising to $1.5-2.0 \mathrm{~m}$ at Laizhou Bay and Bohai Bay (Zhang et al., 1990). The tidal currents have an average speed of $0.5-1.0 \mathrm{~m} / \mathrm{s}$, and move in paralleling to the coast in the form of reciprocating flows (Bi et al., 2010a). In the northeast and middle transects off the present YR delta, the currents flow southward during the flood tide and northward during the ebb tide (Bi et al., 2014). The shear fronts between YR plume and coastal water with different flow directions and velocities have been observed in YR estuary (Li et al., 2001). Time-series data and water samples simultaneously observed in 1995 demonstrated the hindrance effect of tidal shear fronts on the suspended sediment dispersion of around YR estuary (Wang et al., 2007). The northern winds in winter season and prevailing southern wind during summer could drive the sea surface residual current moving northward and southward respectively at an average speed of $0.2 \mathrm{~m} / \mathrm{s}$ (Bi et al., 2014), which has been demonstrated as the dominant force controlling the seasonal variation of YR plume (Wang et al., 2008). The strong wind could also generate surface waves in this area. The wave impact on YR plume during summer was considered to be negligible since the wind mainly blew from land to sea (Wang et al., 2014).

\subsection{Field measurements}

Three hydrographic surveys were conducted during June 10-July 20, which covered the period of WSR in year 2014. The sampling sites were shown in Fig. 1. Salinity, temperature, depth, and turbidity were measured on site with RBR concerto CTD system at sampling frequency of $6 \mathrm{~Hz}$. The CTD instrument was calibrated using the standard protocols and was attached to a rosette. The database of CTD profiles was subjected to quality controls, which included the removal of spurious data by visual inspection and low-pass filtering with a moving-median filter. The salinity and turbidity obtained for sea surface layer were calculated as the average of readings between $0.5 \mathrm{~m}$ and $1 \mathrm{~m}$ below water, because the measurements of $0-0.5 \mathrm{~m}$ below surface were frequently interfered by the sea surface shaking.

Daily river runoff and suspended sediment concentration (SSC) in Fig. 2 were recorded at the Lijin Station, which is the nearest hydrological station located $\sim 100 \mathrm{~km}$ upstream river mouth. Release of water from the Xiaolagndi Reservoir started from June 30 and lasted until July 6 . The daily total water discharge started from $380 \mathrm{~m}^{3} / \mathrm{s}$ before WSR and rise to peak flow of $3320 \mathrm{~m}^{3} / \mathrm{s}$ on July 7 . The suspended particulate matter (SPM) in Fig. 2 also exhibited variability with minimum and maximum values of $750 \mathrm{mg} / \mathrm{L}$ and $8360 \mathrm{mg} / \mathrm{L}$. The peak suspended sediment concentration was 6 days lag behind the peak flow. 


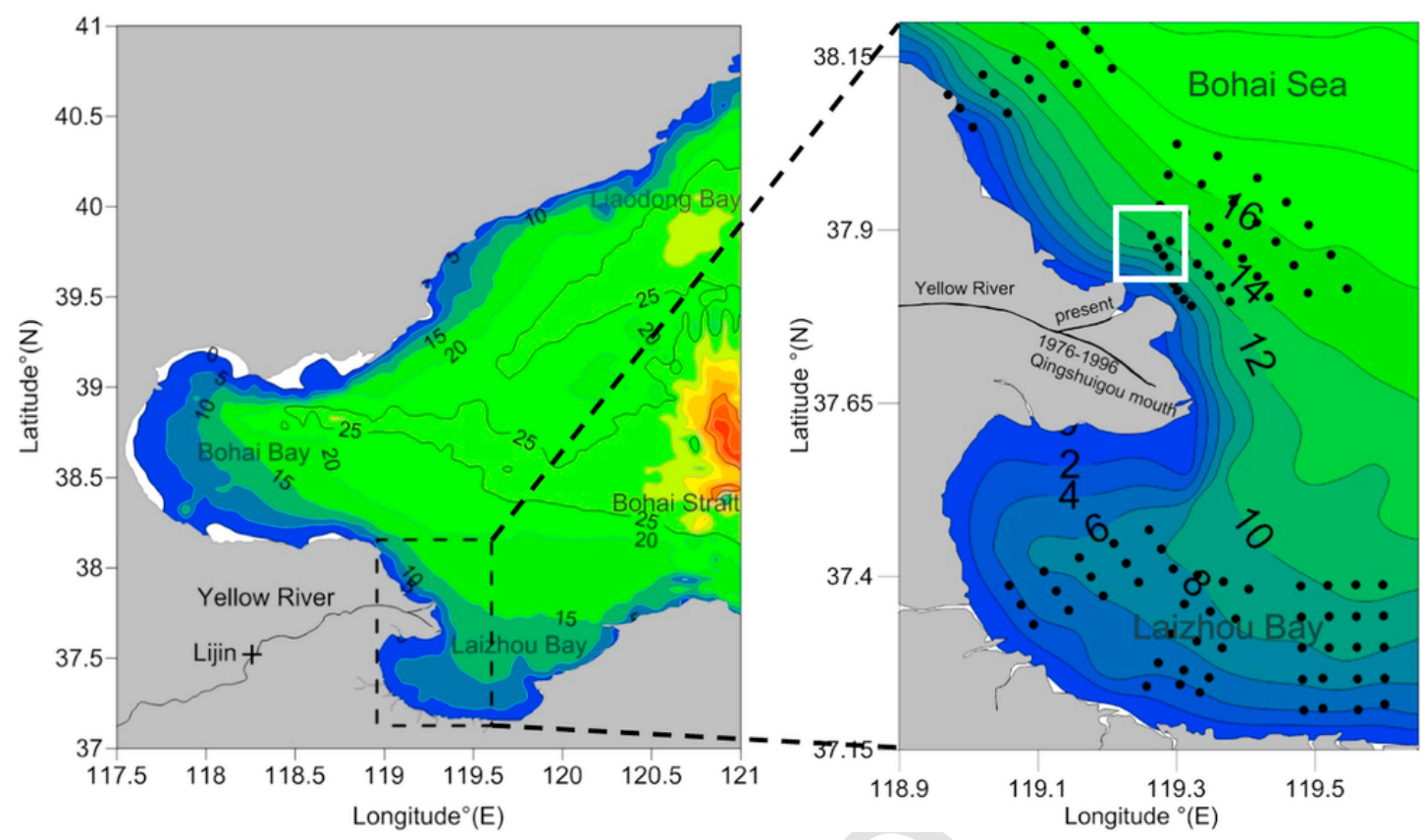

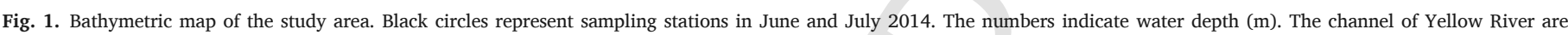
depicted as solid curves.

(a)

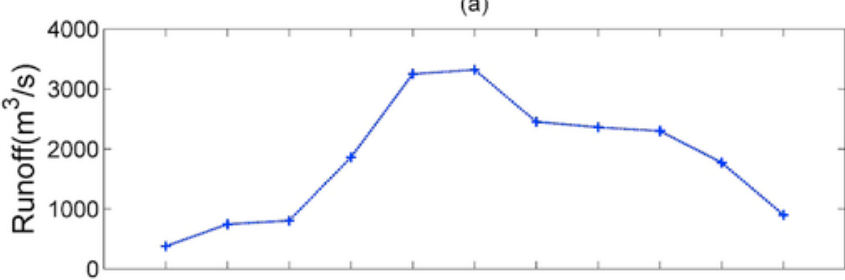

(b)

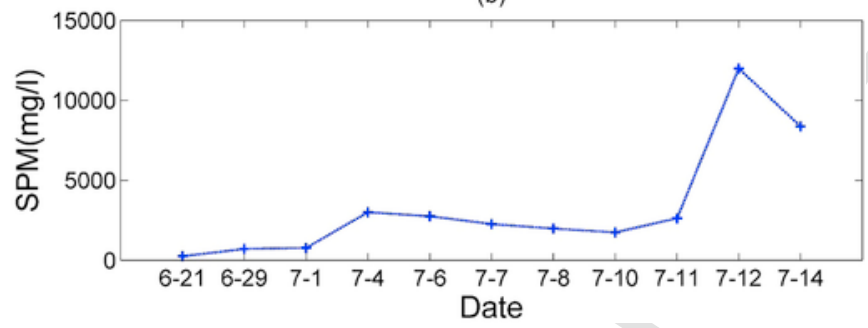

Fig. 2. Yellow River daily (a) runoff and (b) concentrations of suspended particulate matter (SPM) recorded at Lijin Station over the period Jun 21 to Jul 15, 2014.

\subsection{Satellite data}

\subsubsection{MODIS reflectance}

The MODIS L2G products were used in this study to detect YR flume, which had been radiometrically corrected for the variations in atmospheric gases and aerosols to yield surface spectral reflectance (SR) (Petus et al., 2014; Park and Latrubesse, 2014). These daily products provide surface reflectance at 250-m resolution for band 1 $(620-670 \mathrm{~nm})$ and $500-\mathrm{m}$ resolution for band $4(545-565 \mathrm{~nm})$. We used band 1 as a qualitative proxy for amounts of turbidity (sediment dominated) levels, because earlier studies has found that reflectance centered on $645 \mathrm{~nm}$ had high and constant sensitivity to suspended particles and was often integrated into empirical bio-optical algorithms to quantify the total suspended sediment $(\mathrm{mg} / \mathrm{L})$ or turbidity levels (NTU) (Lahet and Stramski, 2010; Aurin et al., 2013; Park and
Latrubesse, 2014; Petus et al., 2014; Fernández-Nóvoa et al., 2015). Band 4 was used for depicting sea surface salinity patterns, because SR at the green-blue range is a better indicator of surface salinity than other visible spectrum wavelengths (Hu et al., 2004; Ahn et al., 2008; Palacios et al., 2009). For this study, a total of 42 scenes covering YR estuary were downloaded with each image acquisition date corresponding to the date of field survey. The satellite data were processed in three steps: (1) selecting the clear satellite images with non-cloud pixels in the region of interest; (2) geometric reprojection of study area subset scenes using SEADAS software; (3) filtering the scenes severely contaminated by clouds/extreme atmospheric conditions and nearshore resuspension.

\subsubsection{GOCI reflectance}

The GOCI is the world's first ocean color observation satellite placed in a geostationary orbit, which provides 8 images each day with a 500-m spatial resolution at hourly interval since it was launched in June 2010 (Choi et al., 2012; He et al., 2013). GOCI is considered to be exclusive and specific in identifying spatiotemporal dynamics of river plume on hourly time scale. Because the red or NIR band is more sensitive to coastal waters containing high turbidity, the surface reflectance of band 5 centered at $660 \mathrm{~nm}$ can provide the hourly observation of turbid plume (Choi et al., 2012). This band has a low penetration in the water and hence avoids bottom influence in shallow water (Lahet and Stramski, 2010). The L1B data was downloaded and then processed to L2 data using the GOCI data processing software (GDPS) with default parameters and standard atmospheric and geometric correction, generating the spectral remote sensing reflectance products for analysis of the hourly dynamics of YR turbid plume.

\subsubsection{ASCAT wind field}

The Advanced Scatterometer (ASCAT) neutral stability winds $10 \mathrm{~m}$ above sea level were provided by NOAA/NESDIS utilizing measurements from ASCAT aboard the EUMETSAT METOP satellite since launch time 2007. Based on standard products ASCAT L2B $12.5 \mathrm{~km}$, the averaged gridded L3 fields having spatial resolutions of $0.25^{\circ}$ at global scale are used in this study. The calculation of daily estimates 
uses ascending as well as descending valid retrievals and the L3 format data were recorded for locations near YR delta.

\subsection{Salinity retrieval}

Match-up of field collected salinity data and digital reflectance derived from satellite imagery is based on the rules established by previous studies (Cui et al., 2010; Qing et al., 2013). A $3 \times 3$ window centered on each sampling site is used with time lag between the satellite overpass and field measurement less than $3 \mathrm{~h}$. The average value from 9 satellite pixels of MODIS was calculated as the reflectance on each sampling sites. Totally 33 groups of matched data were selected for model construction. The multi-regression model for surface water salinity prediction is expressed below:

$\lg ($ Salinity $)=-0.131 \times \frac{S R_{645}}{S R_{555}}+1.499$

The salinity in Eq. (1) is in psu, and $S R_{645}$ and $S R_{555}$ are the reflectance values derived from band 1 and band 4 . Band $1\left(S R_{645}\right)$ is used here for normalizing purposes because CDOM influence on Band 1 is quite low (Kutser et al., 2005; Choi et al., 2012), and previous studies have demonstrated the benefit of including this red-green band to monitor water quality (e.g. CDOM) in estuarine and coastal waters (Bowers et al., 2004; Kutser et al., 2005; Lahet and Stramski, 2010). The $\overline{\text { model }}$ reveals a strong empirical relationship between the salinity and the reflectance with high correlation coefficient $\left(\mathrm{R}^{2}=0.84\right)$ and low residual in fitting the model (RMSE $=0.82$ psu) (Fig. 3a)

\subsection{Turbidity retrieval}

The relationship between field measurements of turbidity and reflectance data from MODIS imagery was established using protocols same as SSS retrieval. Surface turbidity was estimated as a function of atmospherically corrected reflectance values at $645 \mathrm{~nm}$ :

$\lg ($ Turbidity $)=9.96 \times S R_{645}+0.61$

In Eq. (2), turbidity is denoted in NTU and unit of $S R$ centered on $645 \mathrm{~nm}$ is sr ${ }^{-1}$. The upper limit in Eq. (2) is $112 \mathrm{NTU}$ (Fig. 3b), which is lower than the maximum turbidity (429 NTU) recorded in-situ. Therefore in following discussion we would use $S R_{645}$ as a proxy for turbidity levels. This approach of turbidity represented by SR has been used for the remote-sensing of turbid waters in various studies (Lahet and Stramski, 2010; Aurin et al., 2013).

\section{Results and discussion}

\subsection{Characterization of YR plume during WSR}

The regression models of Eq. (1) and Eq. (2) were used to estimate the spatial-temporal variability of sea surface salinity and turbidity in the YR estuary. The spatial distribution of sea surface salinity synthesized from MODIS reflectance data is illustrated on Fig. 4 from June 27 to July 14, 2014. Before WSR (June 27 to June 30), the main axis of salinity plume was predominantly concentrated in front of the river mouth. The salinity distribution was consistent with numerical simulation results of YR salinity plume in summertime (Wang et al., 2008), especially the 26-27 psu isohaline profile. During WSR (July 6 and 7), the remote sensing results demonstrated a drastic northward extension of the low salinity plume. The decrease of salinity in the estuary corresponded with freshwater release from upstream reservoirs, which started from July 1 to July 14 with a peak discharge of $3320 \mathrm{~m}^{3} / \mathrm{s}$ (see Fig. 2a). This dynamic responds of salinity plume were in accordance with field measurement during 2007 WSR (Bi et al., 2010b). On July 14 the river discharge decreased to $900 \mathrm{~m}^{3} / \mathrm{s}$ at the end of $2014 \mathrm{WSR}$. The post WRSE salinity pattern in YR estuary was illustrated on the image of July 14 , which shows a shrink of plume area.

Image sequence of MODIS $S R_{645}$ as a proxy for turbidity levels showed an increasing trend in turbid area during WSR (Fig. 5). The high turbidity region under pre-WSR condition (June 27 to June 30) could be identified as bulges near the river mouth. The images of July 6 to July 7 illustrated that plume area sharply extended to the north, which was close to the observation during 2009 and 2012 WSR (Yu et al., 2013). As depicted on Fig. 2b, the maximum suspended sediment concentration $\left(1.2 \times 10^{4} \mathrm{mg} / \mathrm{L}\right)$ was observed on July 13 at Lijin Station, 6 days behind peak freshwater discharge. Similar asynchronous arrival of sediment and freshwater discharge had been observed during the (a)

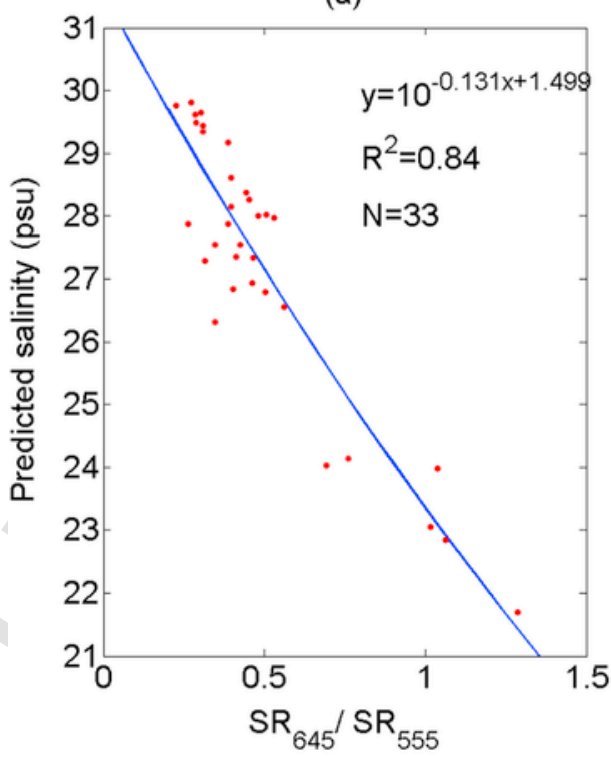

(b)

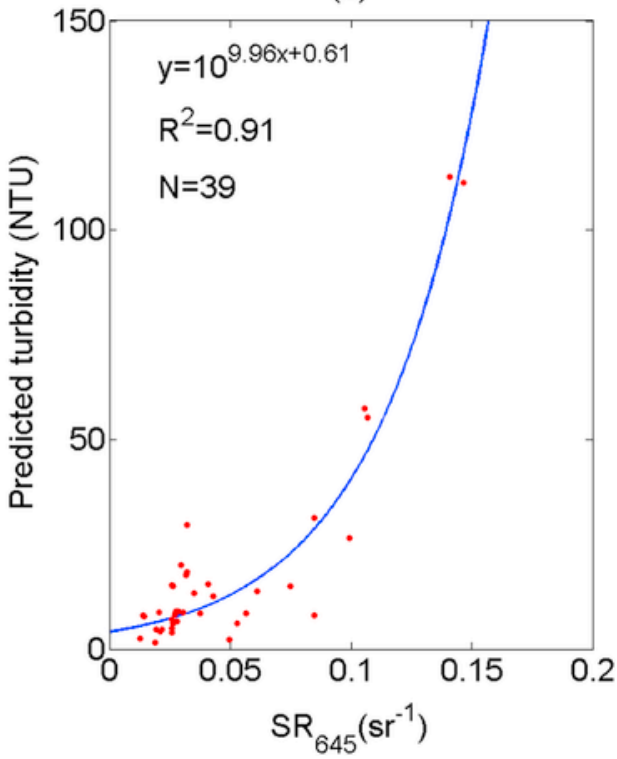

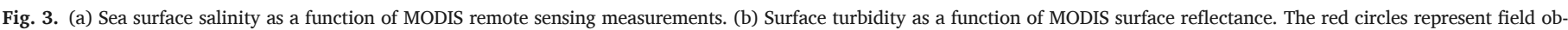

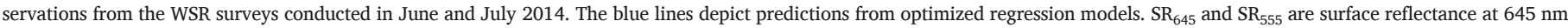
and $555 \mathrm{~nm}$, respectively. (For interpretation of the references to color in this figure legend, the reader is referred to the web version of this article.) 

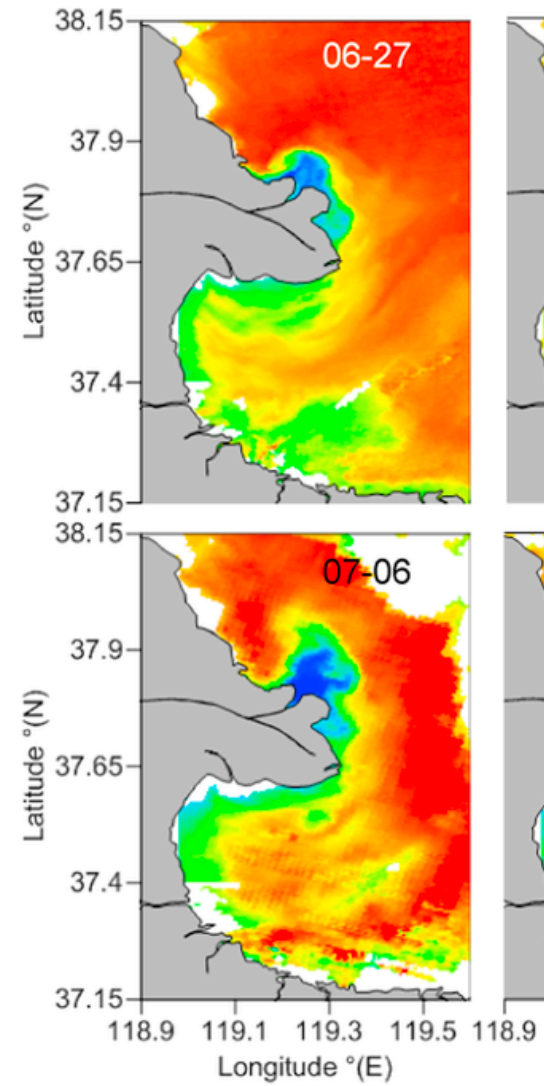
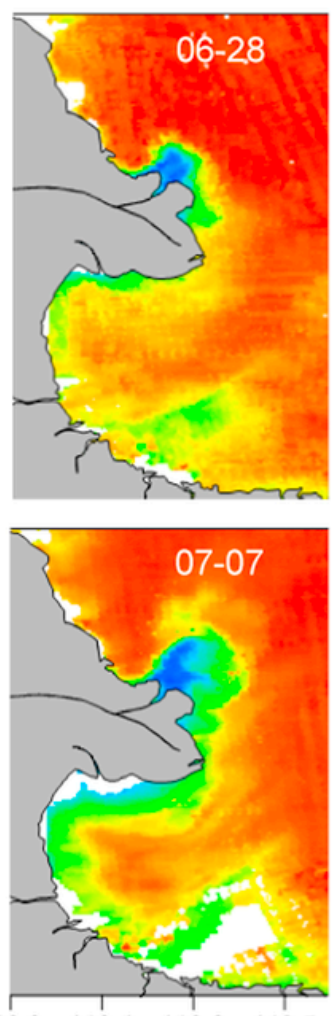

$\begin{array}{ll}119.1 & 119.3 \\ \text { Longitude } & \\ & \end{array}$
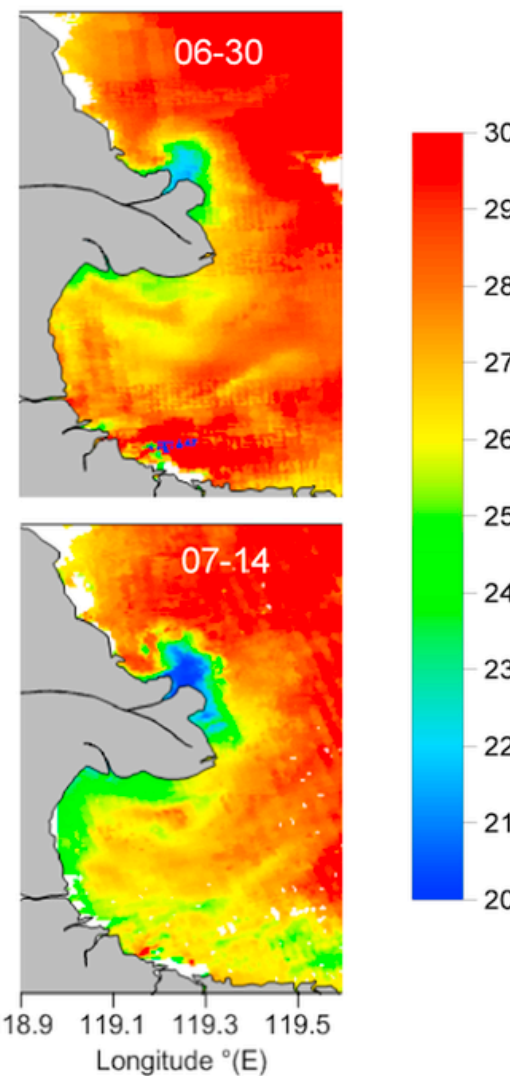

Longitude ${ }^{\circ}(\mathrm{E})$

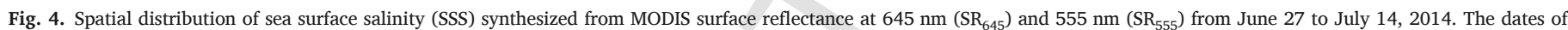
image acquisition are indicated on upper right corner of each plot. White pixels are areas with invalid data due to cloud mask or nearshore resuspension. Land is shown in grey.

previous WSR and was attributed to the fact that majority of suspended sediment was coarse particles transported as bed load during the artificial flooding (Bi et al., 2010b). This significant difference in transport of freshwater and sediment explained the disparities between the estimated extent of salinity and turbidity plume.

During the WSR, YR flood delivered tremendous amounts of sediments and CDOM from upstream reservoirs and stream channels to the estuary. These two substances are the major factors to alter optical reflectance in water surface. The suspended particles scatters the reflectance of solar radiation in the red and near-infrared portions of the spectrum, while the CDOM absorbs light in the lower wavelengths (Palacios et al., 2009; Lahet and Stramski, 2010; Petus and Marieu, 2014; Park and Latrubesse, 2014). The results from 2014 WSR proved that band $1(620-670 \mathrm{~nm})$ and band $4(545-565 \mathrm{~nm})$ of MODIS could capture the dynamics of salinity and sediment in YR plume in response to the abrupt change of freshwater and sediment load due to artificial flooding. The satellite remote sensing products provided a valuable dataset to analyze the physical factors influencing the short term variation of river plume.

To quantify the variability of plume area and direction, threshold values of salinity and turbidity for delineating plume boundary were determined based on the linear regression analysis between calculated plume areas and freshwater discharges (Lahet and Stramski, 2010; Fernández et al., 2015). The correlation coefficients $R^{2}$ were plotted as a function of threshold values in Fig. 6. A threshold surface salinity at 25 psu was determined with maximum $R^{2}$ in Fig. 6a. In the case of turbidity, the maximum $R^{2}$ occurred on the $S R_{645}$ of $0.12 \mathrm{sr}^{-1}$, which corresponds to turbidity of 64 NTU in Eq. (2).

Using above threshold values, the plume area (PA) and the plume shape (PS) were calculated. The plume areas measured in the number of pixels within the river plume boundary were converted to unit of $\mathrm{km}^{2}$ by multiplying with grid resolution. The plume shapes were calculated as main angle of plume direction by application of Linear Direction Mean function on the polygons delineating the plume occupied region (Molleri et al., 2010). The calculated PA and PS are plotted as a function of image dates in Fig. 7.

\subsection{Responses to freshwater and sediment discharges}

As illustrated in Fig. 7, the low salinity plume area ( $<25$ psu) increased to $267 \mathrm{~km}^{2}$ on July 7, corresponding to the peak of river inflow, then decreased to about $150 \mathrm{~km}^{2}$ on July 14 as the flood from WSR receded. The significant correlation between plume area and river discharge $\left(R^{2}=0.96\right)$ indicated that inter-day variability of YR plume is largely controlled by upstream release of freshwater. Freshwater mainly accumulated in front of the river mouth (Fig. 4) and reduced the average salinity of YR estuary by $\sim 2.5$ psu (Fig. 7 ). The plume shape exhibited no significant correlation with discharge, which suggested that variation of plume shape is not controlled by river flow. The turbid plume area $\left(S R_{645}>0.12 \mathrm{sr}^{-1}\right)$ extended from $82 \mathrm{~km}^{2}$ before WSR to a maximum of $162 \mathrm{~km}^{2}$ on July 7, 2014. However, the average turbidity of the YR estuary further increased until July 14 . The results indicated that majority of sediment carried by YR deposited in a rather small area in front of the delta, which was consistent with the observation that large fraction of the YR sediment consisted of coarse particles. Nevertheless, the increasing surface turbidity throughout WSR event indicated that a considerable amount of fine sediment was carried into the estuary, which might change the biochemical and ecological function of the coastal water. 

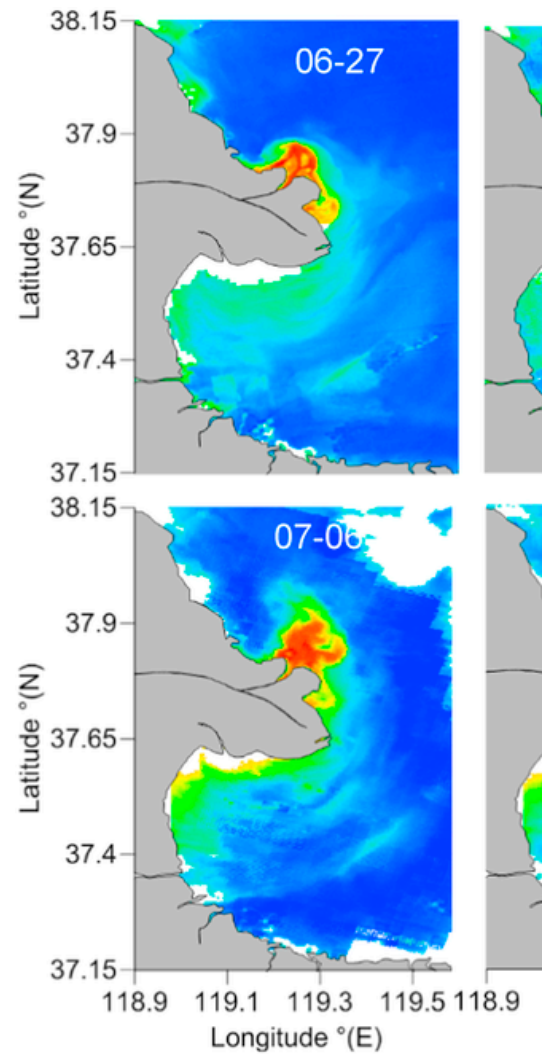
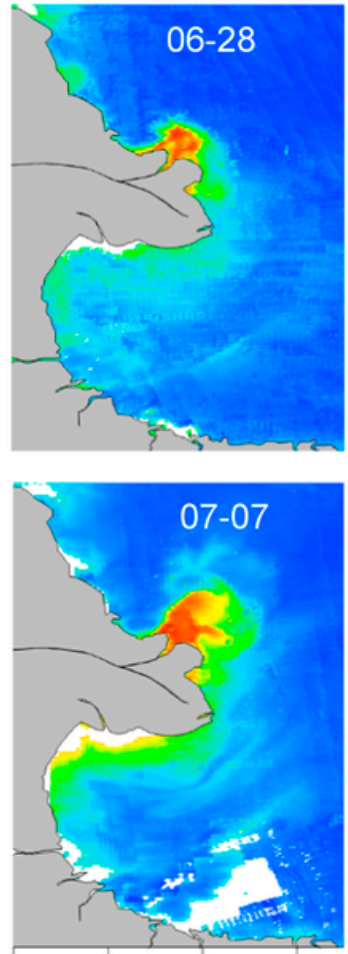

119.1119 .3
Longitude ${ }^{\circ}(\mathrm{E})$
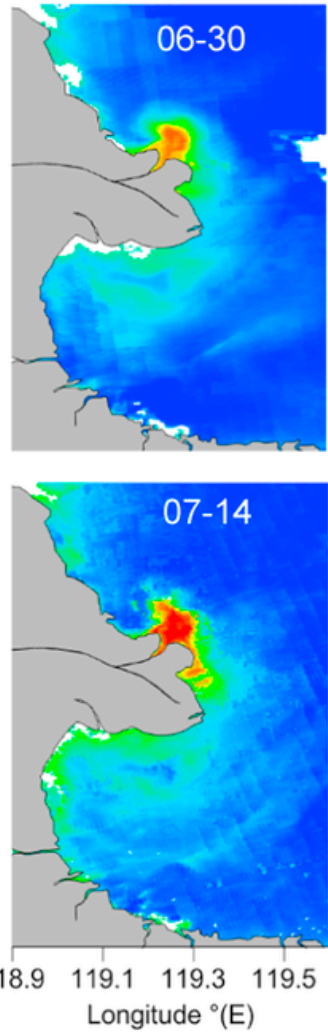

Longitude ${ }^{\circ}(E)$

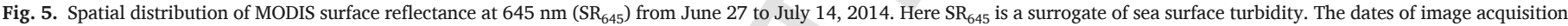
are indicated on upper right corner of each plot. White pixels are areas with invalid data due to cloud mask or nearshore resuspension. Land is shown in grey.
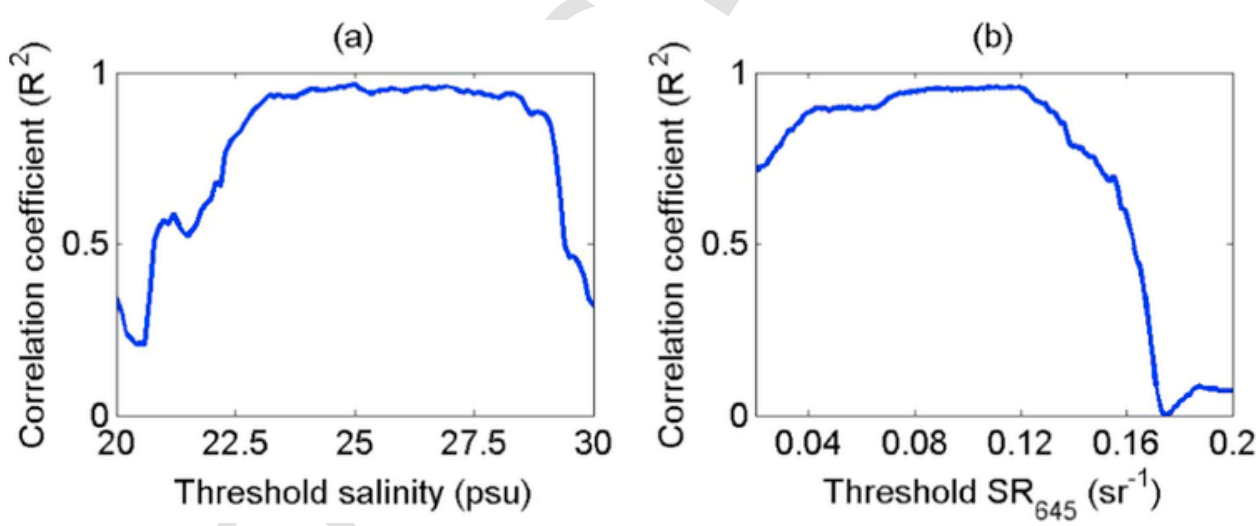

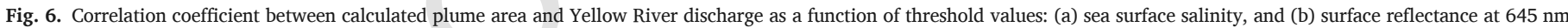
$\left(\mathrm{SR}_{645}\right)$ as a surrogate of sea surface turbidity.

\subsection{Effect of Coriolis force and wind-driven circulation}

Modelling and observational studies of surface plumes showed buoyant outflow spreading radially offshore from its source, rotating anticyclonically, and then subsequently being deflected to the right in the northern hemisphere by Coriolis force (Hopkins et al., 2013). The results in Figs. 4 and 5 illustrated that the YR buoyant plume was strongly driven by the Coriolis force, which promoted the anticyclonic turning around the YR delta and the downstream current along the western coasts of Laizhou Bay. These patterns had been identified in early numerical studies on YR plume dynamics in the presence of buoyancy forcing only (Wang, 2008). As result, the anticyclonic bulge and the downstream coastal current carried plume waters towards the western or even south shelf of Laizhou Bay.
The dependence of YR plume on summertime wind force can be described with wind-driven currents (Hopkins et al., 2013). The Ekman surface currents $(V, \mathrm{~m} / \mathrm{s})$ were calculated from the ASCAT wind fields using the formula:

$V=\frac{E}{\rho \sqrt{N_{z}|f|}}$

where $E$ is the wind stress magnitude in $\mathrm{Pa}, \rho$ is the water density in $\mathrm{kg} / \mathrm{m}^{3}$, and the eddy viscosity $N_{z}$ near the YR estuary is taken as $0.0023 \mathrm{~m}^{2} / \mathrm{s}$ (Wang et al., 2011), $f$ is the Coriolis frequency in $\mathrm{s}^{-1}$. The calculated daily wind-induced surface Ekman current fields around YR delta in Fig. 8 did not show significant correlation with plume area or shape. This suggested that influence of wind field on the YR plume variability is relatively small, which is inconsistent with previous nu- 

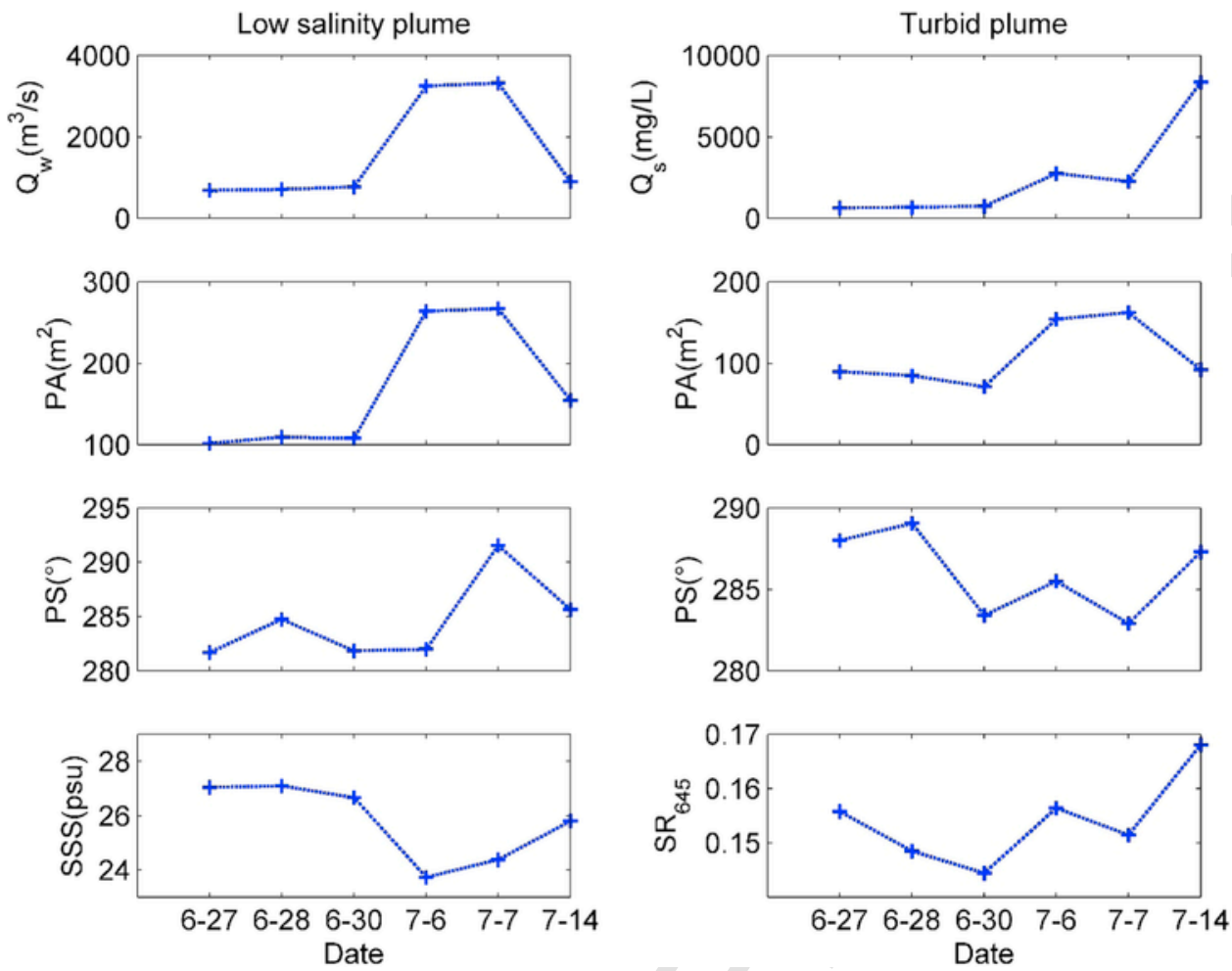

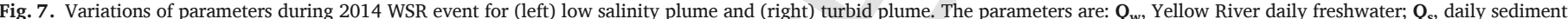
discharge; PA, plume area $\left(\mathrm{km}^{2}\right)$; PS, plume direction $\left({ }^{\circ}\right)$; $\mathbf{S S S}$, sea surface salinity; and $\mathbf{S R}_{\mathbf{6 4 5}}$, surface reflectance at $645 \mathrm{~nm}$ as a surrogate of sea surface turbidity.
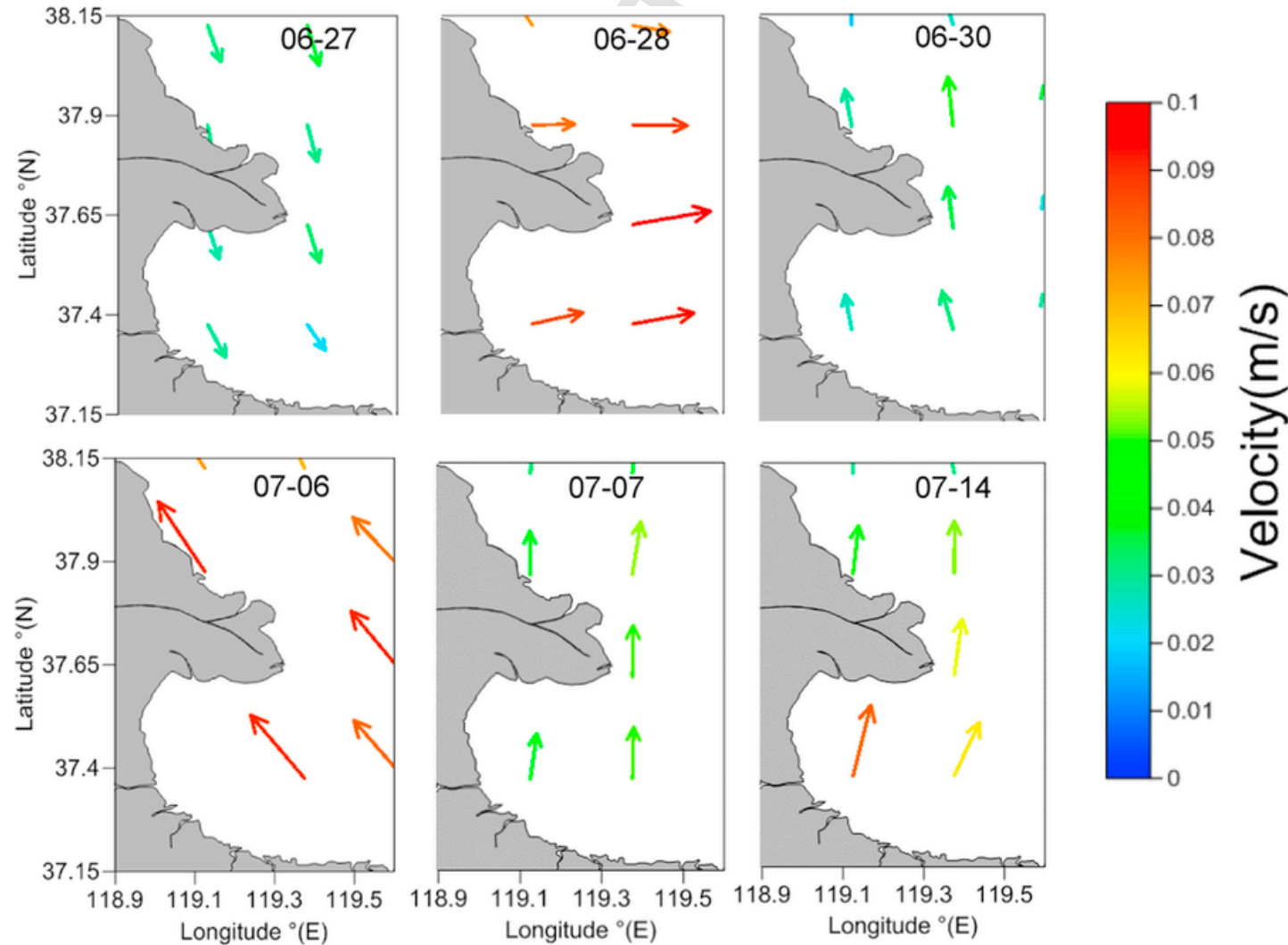

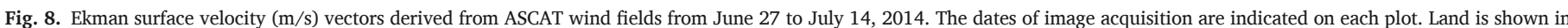
grey. 
merical experiments (Wang et al., 2008). In their modeling study, Wang et al. (2008) applied southeasterly wind at constant magnitudes from June 1 to September 30 and found a strong dependence of the YR plume on magnitude of summertime wind stress. However, the wind field observed from ASCAT showed the summertime wind in the estuary was short-lived and of low magnitude. The weak winds blowing from delta to sea were further calmed down by terrestrial friction before inducing seaward movement of YR plume.

\subsection{Intraday responses to tidal currents}

In order to monitor the impact of tidal cycle, the hourly variability of YR turbid plume were estimated from GOCI L2C products. The surface reflectance at $660 \mathrm{~nm}\left(S R_{660}\right)$ of band 5 were used as indicator of turbidity and displayed on Figs. 9 and 10. On July 6, the turbid plume flowed westward at 0:16 (GMT), then gradually moved eastward until 3:16, followed by shifting back westerly and extending offshore (Fig. 9). Turbid plume on July 7 demonstrated a similar swing feature, with the shift occurring one hour later on $4: 16$ (Fig. 10). The tidal regime
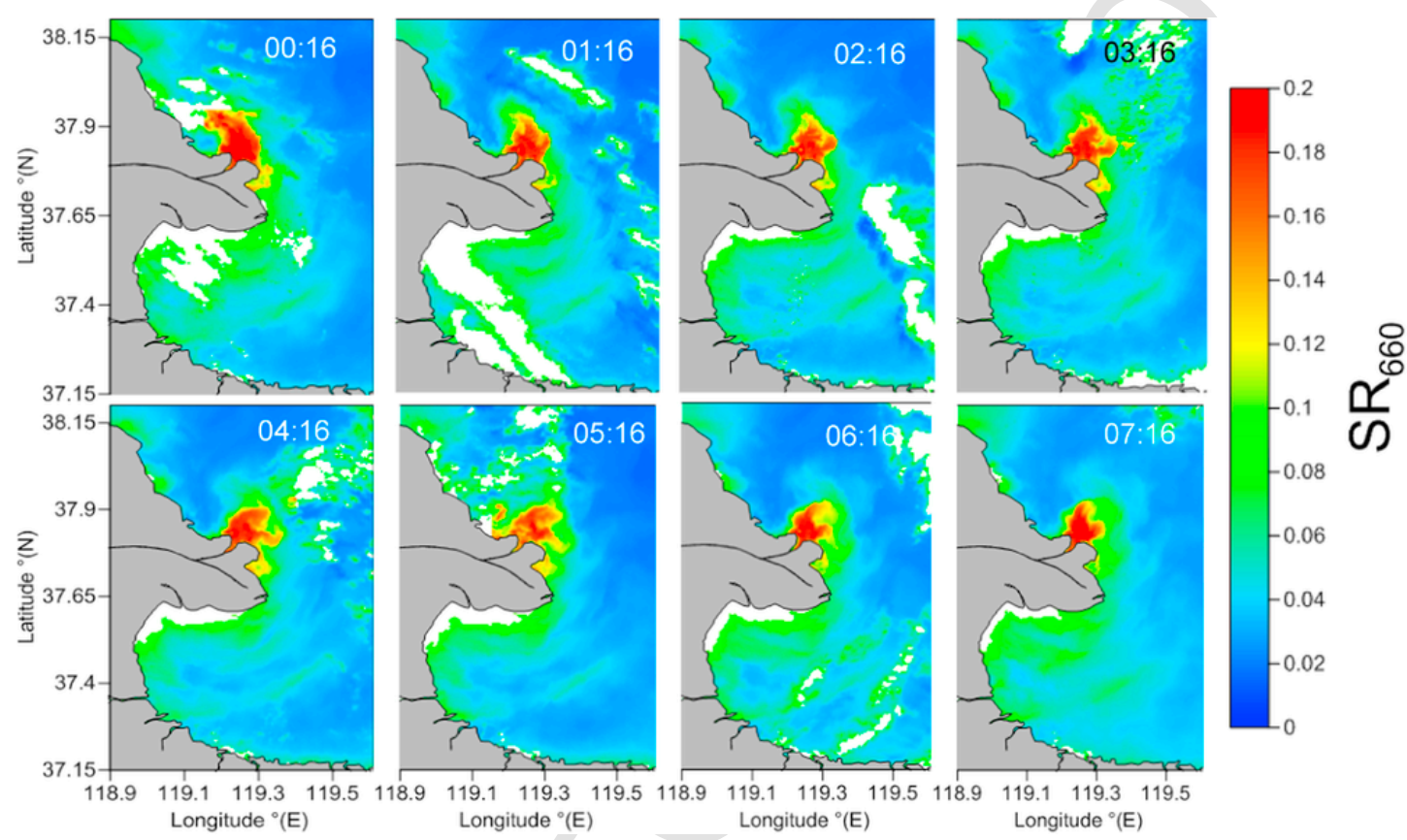

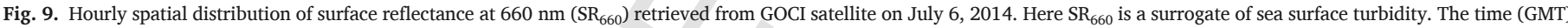
of image acquisition are indicated on each plot. White pixels are areas with invalid data due to cloud mask or nearshore resuspension. Land is shown in grey.
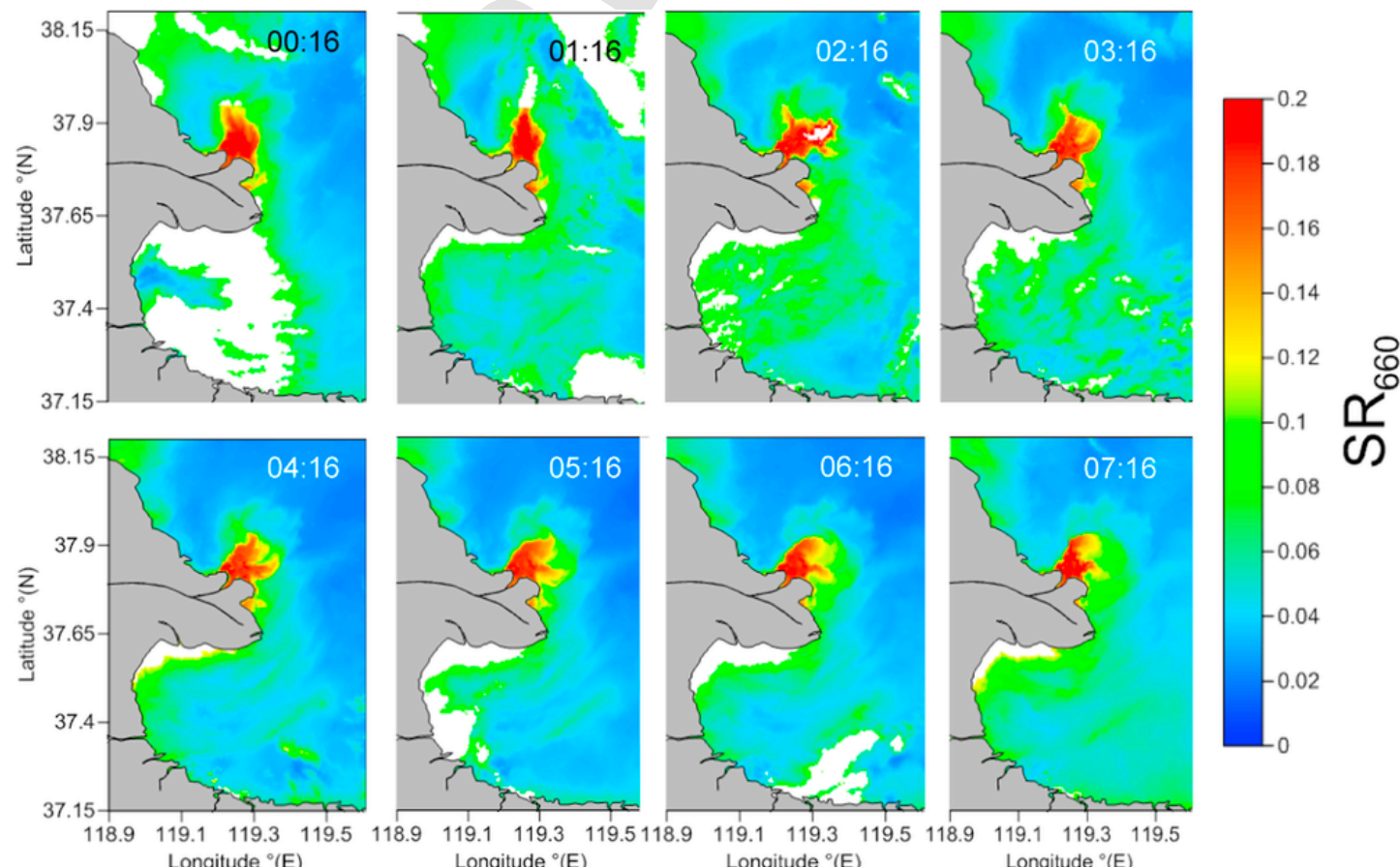

Fig. 10. Same as Fig. 10, but for July 7, 2014. 
July 6

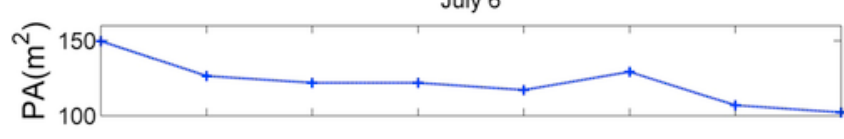

July 7

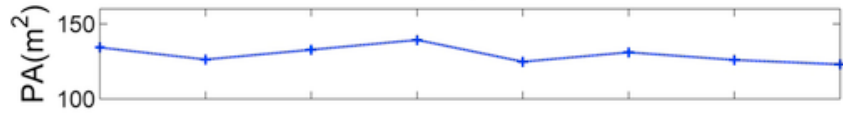

July 6

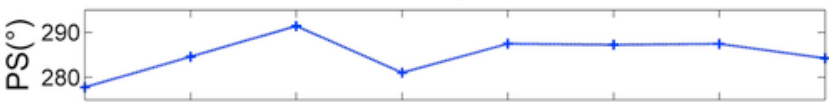

July 7

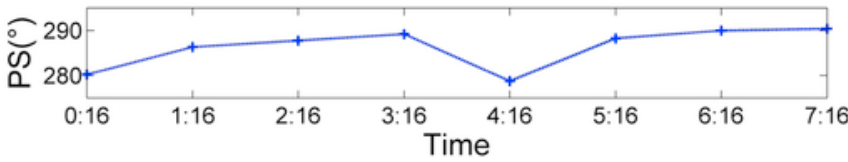

Fig. 11. Hourly variation of calculated Yellow River turbid plume area (PA) and plume direction (PS) on July 6 and July 7, 2014. The metrics are calculated from surface reflectance at $660 \mathrm{~nm}\left(\mathrm{SR}_{660}\right)$ retrieved from GOCI satellite (Figs. 9 and 10) using 0.12 as the threshold value.

near YR plume was dominated by an irregular semidiurnal tide with a tidal cycle of about $6 \mathrm{~h}$ (Bi et al., 2010a). This variance of plume pattern corresponded to the tidal flow progressing from flood to ebb. Our analysis showed that intraday YR plume dynamics could be clearly captured by GOCI reflectance images. Meanwhile, the shape of turbid plume covaried with tidal flow, suggesting that tide was a major factor controlling spatial distribution of river discharge in estuary.

Threshold of $0.12 \mathrm{sr}^{-1}$ was used to calculate turbid plume area and shape on GOCI band 5. The results are displayed as a function of time on Fig. 11. The mean turbid plume areas were $129.6 \mathrm{~m}^{2}$ and $143.5 \mathrm{~m}^{2}$ on July 6 and 7, respectively, which were smaller than plume area estimated by the salinity indicator and close to the result from MODIS band 1 (Fig. 7). The most dramatic change of plume shape on July 6 occurred on 2:16 to 3:16 corresponding to shift of tidal flow. The observed variation of plume shape on July 7 was consistent with July 6 but with $1 \mathrm{~h}$ delay. Our analysis validates that quantitative estimation of tidal currents in estuaries is feasible based on dispersal pattern of turbid plume (Choi et al., 2012).

\subsection{Inter-annual variations}

To further investigate the inter-annual variation of YR turbid plume, MODIS data during WSR in year 2004 and 2009 were also processed. Spatial distributions of synthesized surface salinity and $\mathrm{SR}_{645}$ at different dates are displayed on Figs. 12 and 13. Substantial variation of plume area was observed between three years, which well corresponded to the scale of WSR in selected years. On June 29, 2004, both the low salinity and turbid plume extended further north, covering a maximum area of $367 \mathrm{~km}^{2}$, while the maximum plume area in 2009 was merely $179 \mathrm{~km}^{2}$. The WSR in 2004 started from June 19 and ended on July 13 with a total freshwater discharge of $4.8 \times 10^{9} \mathrm{~m}^{3}$ and sediment load of $7.0 \times 10^{7} \mathrm{Mg}$. In comparison, WSR in 2009 was between June 19 and July 7 with a total freshwater discharge of $3.5 \times 10^{9} \mathrm{~m}^{3}$ and sediment load of $4.5 \times 10^{7} \mathrm{Mg}$. The remote sensing results illustrated the transport of freshwater and sediment in the YR estuary and established a rich dataset for calibrating the numerical models. Overall, the satellite remote sensing data were capable of capturing the short term (intraday) as well as long term (inter-annual) variation of YR plume and provided a low-cost and efficient tool for the planning and design of WSR scheme.

\section{Conclusions}

Accurate depictions of water and sediment dynamics in river plumes are crucial for understanding fluvial morphodynamics and environmental characteristics of the river mouth and coastal water. In this study, MODIS and GOCI satellite products were processed to provide a detailed examination of the dynamic of freshwater and sediment in YR estuary during WSR. Surface salinity and turbidity retrieved from the regression analysis well correlated with in-situ measurements, and established reliable indicators of the plume. Threshold values for delineating freshwater and sediment plumes were established for synthesized sea surface salinity ( $<25 \mathrm{psu}$ ) and surface turbidity $\left(S R_{645}>0.12 \mathrm{sr}^{-1}\right)$ based on correlation analysis. The results showed that area of low salinity plume increased from $105 \mathrm{~km}^{2}$ before WSR to $267 \mathrm{~km}^{2}$ as freshwater released from upstream reservoirs reached river mouth. The maximum concentration of suspended sediments was observed 6 days behind the peak flow, which suggested a different transporting mechanism of sediment load. The area of turbid plume $\left(S R_{645}>0.12 \mathrm{sr}^{-1}\right)$ extended from $82 \mathrm{~km}^{2}$ before WSR to a maximum of $162 \mathrm{~km}^{2}$ on July 7, 2014. The cross-correlation analysis confirmed that river discharge is the main factor controlling the plume area.

Hourly GOCI surface reflectance images well depicted the rapid shift of turbid plume in response to reciprocating tidal current. Our analysis established tide as the primary force regulating the intra-day variation of plume direction and shape. The remote sensing data also clearly illustrated anticyclonic turning of buoyant plume around the YR delta and downstream transport toward the west coast of Laizhou Bay, which was explained with Coriolis force and longshore transport. Although the wind driven Ekman transport dominates seasonal variation of plume dispersion, it had little effect on the short term movement of river plume during WSR in summer time.

Overall, remote sensing based on MODIS and GOCI satellite data provided a substantially more detailed quantification of YR plume dynamics, especially the inter- and intraday variation of salinity and turbidity during WSR events. The approach provides a powerful tool for monitoring plume dynamic and its potential impacts on the ecological health of coastal waters over the short-term events caused by climate events or anthropogenic activities.

\section{Acknowledgements}

The authors are thankful for Prof. Maosheng Gao of Qingdao Institute of Marine Geology (QIMG) for organizing the 2014 expedition and appreciate the help of captain, crew and scientists on Haohai 7 in sampling. MODIS data was downloaded from NASA's OceanColor website (http://oceancolor.gsfc.nasa.gov/). GOCI data and GDPS software was provided by the Korea Ocean Satellite Center of KIOST. The ASCAT data was obtained from the Centre de Recherche et d'Exploitation Satellitaire (CERSAT), at IFREMER, Plouzané(France). This study was financially supported by the Strategic Priority Research Program of the Chinese Academy of Sciences (grant no. XDA11020305) and the Key Deployment Project of Chinese Academy of Sciences (grant no. KZZD-EW-14). 

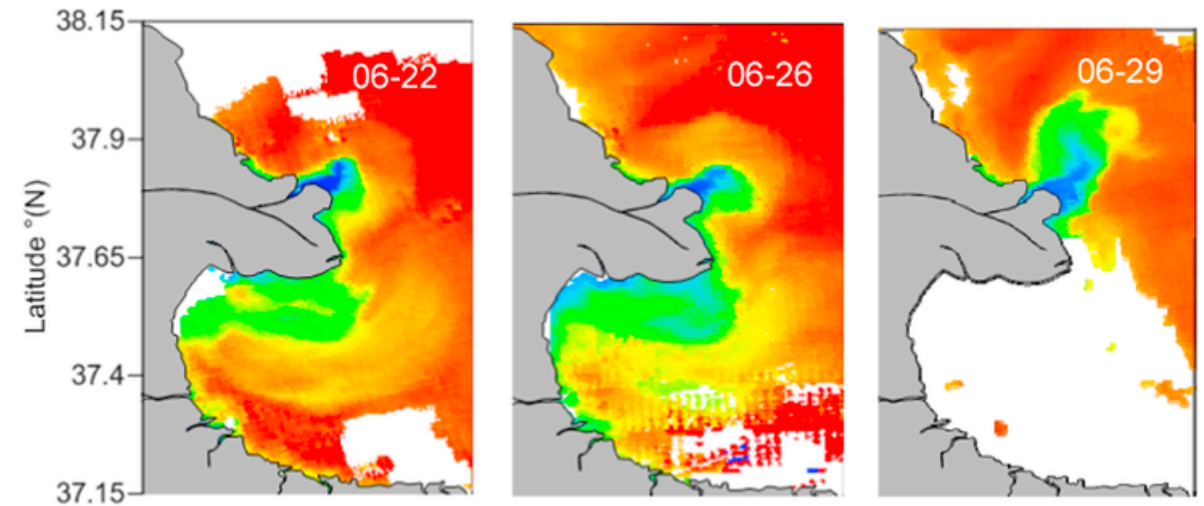

(a)
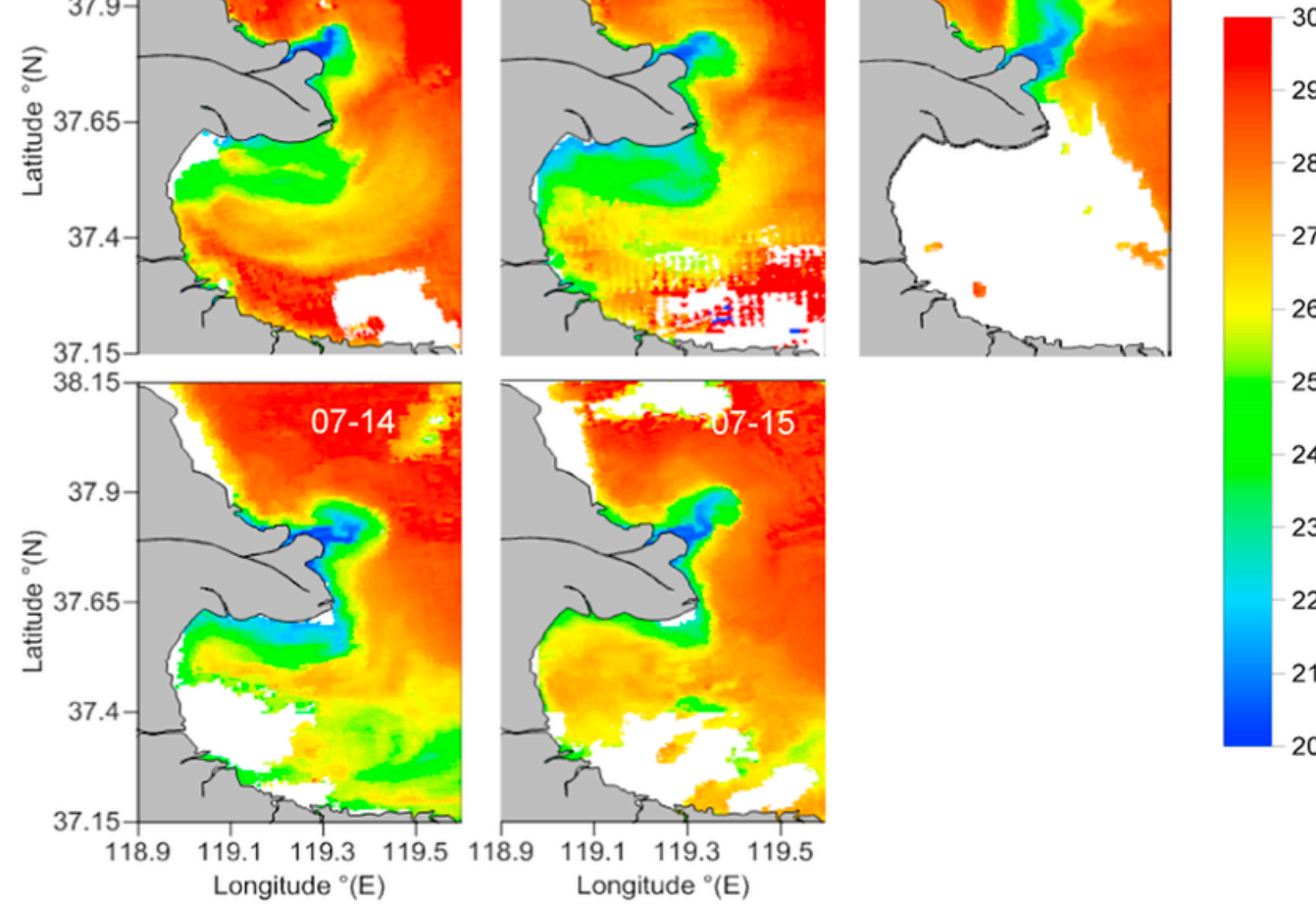

30
29
28
27
26

25

24

(5)

23

22

21

20
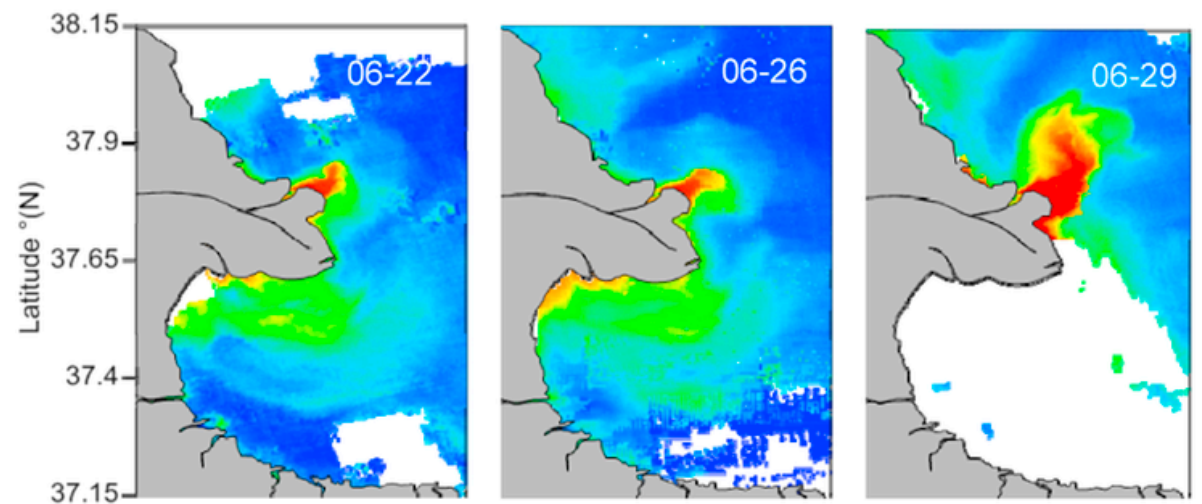

(b)
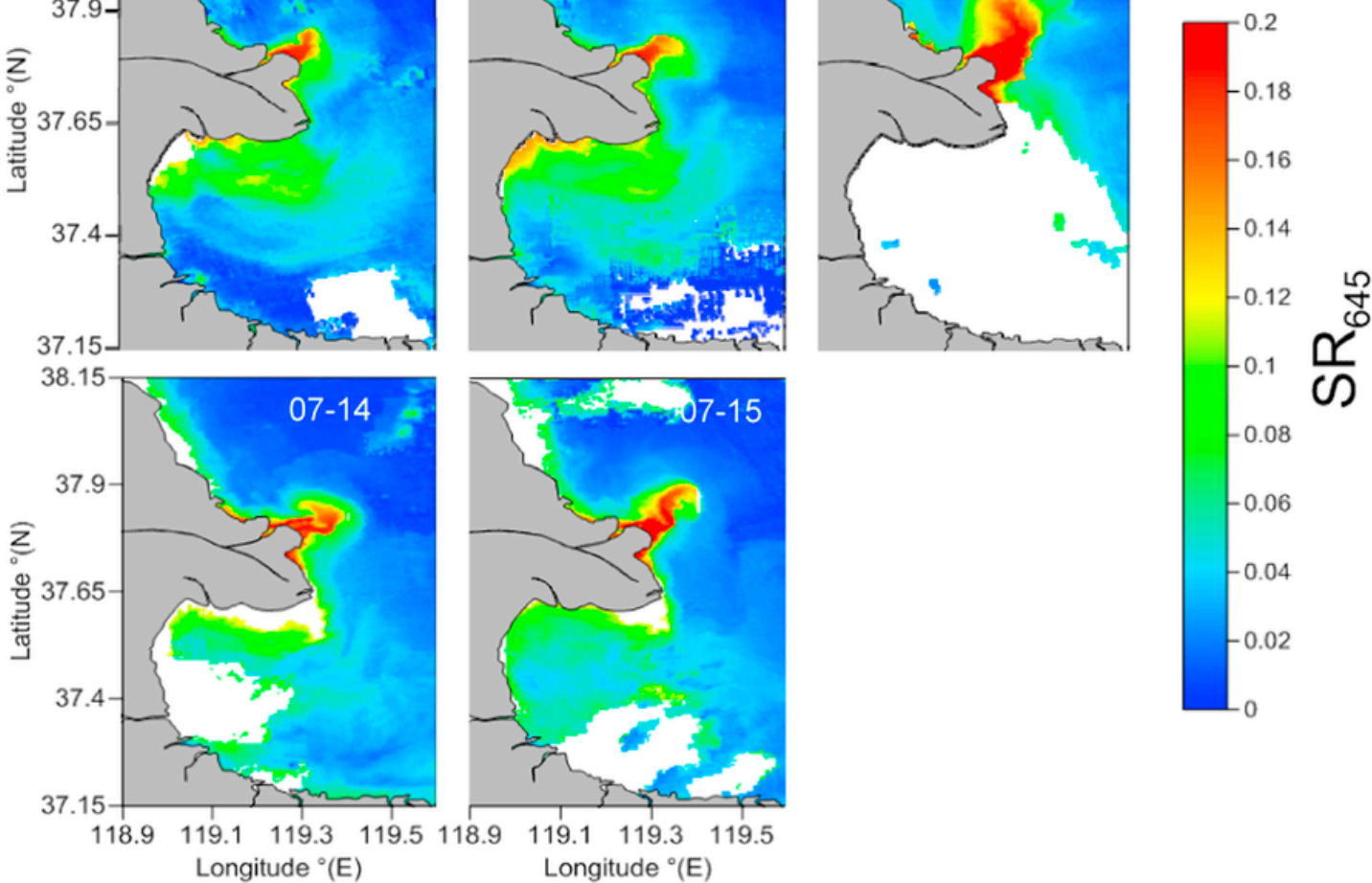

Fig. 12. Spatial distribution of (a) sea surface salinity (SSS) synthesized from MODIS surface reflectance at $645 \mathrm{~nm}\left(\mathrm{SR}_{645}\right)$ and $555 \mathrm{~nm}\left(\mathrm{SR}_{555}\right)$, and (b) MODIS SR 645 from June 22 to July 15 , 2004. Here $\mathrm{SR}_{645}$ is a surrogate of sea surface turbidity. The dates of image acquisition are indicated on upper right corner of each plot. White pixels are areas with invalid data due to cloud mask or nearshore resuspension. Land is shown in grey. 

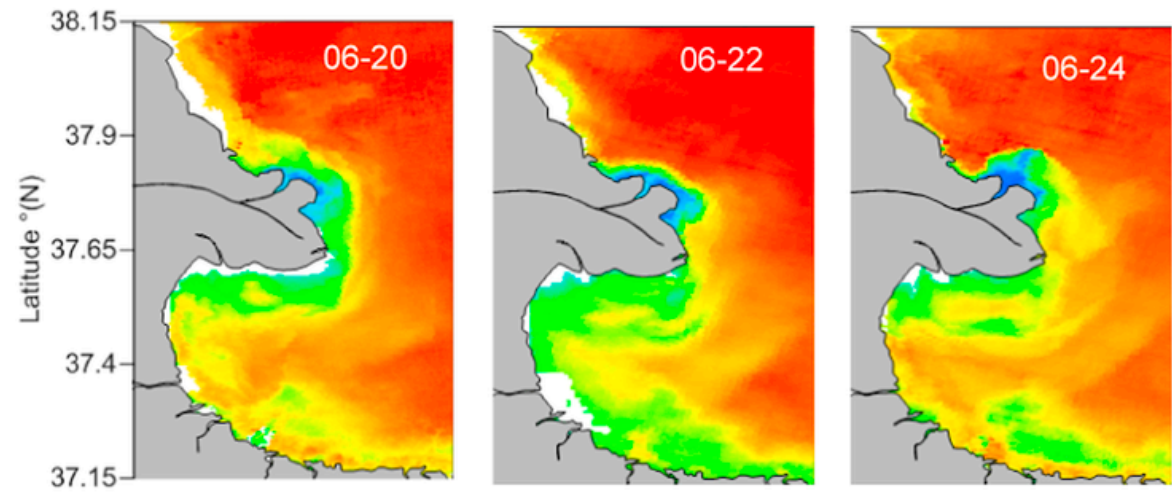

(a)
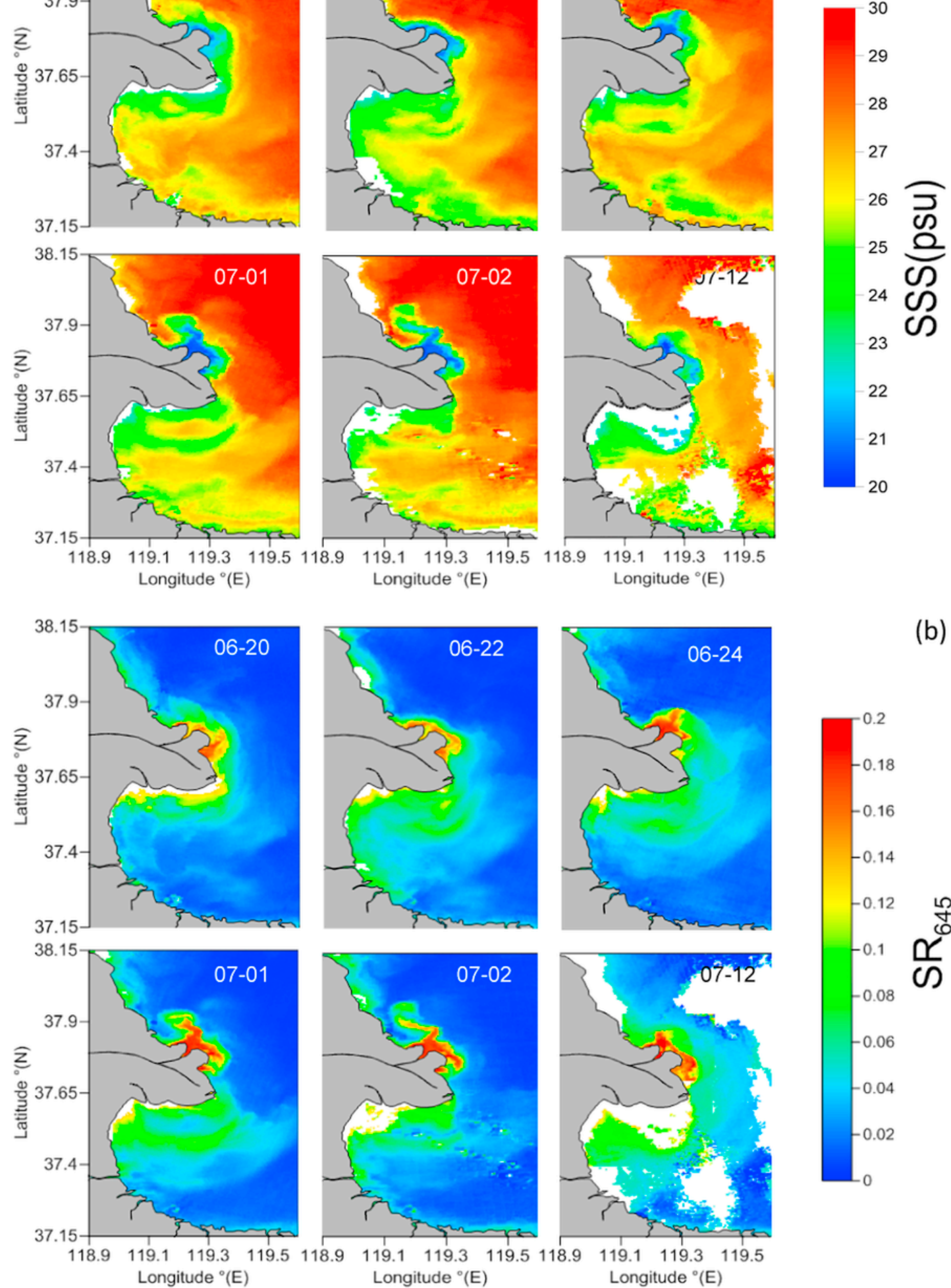

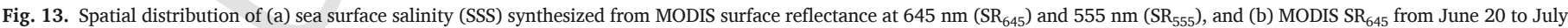

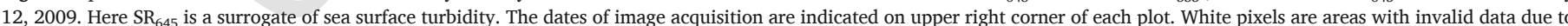
cloud mask or nearshore resuspension. Land is shown in grey. 


\section{References}

Ahn, Y.H., Shanmugam, P., Moon, J.E., Ryu, J.H., 2008. Satellite remote sensing of a low-salinity water plume in the East China Sea. Ann. Geophys. 26, 2019-2035.

Aurin, D., Mannino, A., Franz, B., 2013. Spatially resolving ocean color and sediment dispersion in river plumes, coastal systems, and continental shelf waters. Remote Sens. Environ. 137, 212-225.

Bi N.S. Wang H.J. Yang Z.S. 2014. Recent changes in the erosion-accretion patterns of the active Huanghe (YR) delta lobe caused by human activities Cont. Shelf Res. 90 70-78

Bi, N.S., Yang, Z.S., Wang, H.J., Hu, B.Q., Ji, Y.J., 2010. Sediment dispersion pattern off the present Huanghe (YR) subdelta and its dynamic mechanism during normal river discharge period. Estuar., Coast. Shelf Sci. 86, 352-362.

Bi, N.S., Yang, Z.S., Wang, H.J., Fan, D.J., Ji, Y.J., 2010. Dispersal characteristics of the Huanghe (YR) water and sediment to the sea during Water-Sediment regulation period of the Huanghe and its dynamic mechanism. Mar. Geol. Q. Geol. 30, 27-34 (in Chinese, with English abstract).

Bi, N.S., Yang, Z.S., Wang, H.J., Fan, D.J., Sun, X.X., Lei, K., 2011. Seasonal variation of suspended-sediment transport through the southern Bohai Strait. Estuar., Coast. Shelf Sci. 93, 239-247.

Bowers, D.G., Evans, D., Thomas, D.N., Ellis, K., Williams, P.J., le, B., 2004. Interpreting the colour of an estuary. Estuar, Coast. Shelf Sci. 59, 13-20.

Choi, J.K., Park, Y.J., Ahn, J.H., Lim, H.S., Eom, J., Ryu, J.H., 2012. GOCI, the world's first geostationary ocean color observation satellite, for the monitoring of temporal variability in coastal water turbidity. J. Geophys. Res. 117, C09004. http://dx.doi.org/10. 1029/2012JC008046.

Cui, T.W., Zhang, J., Groom, S., Sun, L., Smyth, T., Sathyendranath, S., 2010. Validation of MERIS ocean-color products in the Bohai Sea: a case study for turbid coastal waters. Remote Sens. Environ. 114, 2326-2336.

Dagg, M., Benner, R., Lohrenz, S., Lawrence, D., 2004. Transformation of dissolved and particulate materials on continental shelves influenced by large rivers: plume processes. Cont. Shelf Res. 24, 833-858.

Fernández-Nóvoa, D., Mendes, R., deCastro, M., Dias, J.M., Sánchez-Arcilla, A., Gómez-Gesteira, M., 2015. Analysis of the influence of river discharge and wind on the Ebro turbid plume using MODIS-Aqua and MODIS-Terra data. J. Mar. Syst. 142, 40-46.

Grimes, C., Kingsford, M., 1996. How do riverine plumes of different sizes influence fish larvae: do they enhance recruitment?. Mar. Freshw. Res. 47, 191-208.

He, X.Q., Bai, Y., Pan, D.L., Huang, N.L., Dong, X., Chen, J.S., Chen, C.T.A., Cui, Q.F., 2013. Using geostationary satellite ocean color data to map the diurnal dynamics of suspended particulate matter in coastal waters. Remote Sens. Environ. 133, 225-239.

Hopkins, J., Lucas, M., Dufau, C., Sutton, M., Stum, J., Lauret, O., Channelliere, C., 2013. Detection and variability of the Congo River plume from satellite derived sea surface temperature, salinity, ocean colour and sea level. Remote Sens. Environ. 139, 365-385.

Hu, C.M., Chen, Z.Q., Clayton, T.D., Swarnzenski, P., Brock, J.C., Muller-Karger, F.E., 2004. Assessment of estuarine water-quality indicators using MODIS medium-resolution bands: initial results from Tampa Bay, FL. Remote Sens. Environ. 93, 423-441.

Kutser, T., Pierson, D.C., Kallio, K.Y., Reinart, A., Sobek, S., 2005. Mapping lake CDOM by satellite remote sensing. Remote Sens. Environ. 94, 535-540.
Lahet, F., Stramski, D., 2010. MODIS imagery of turbid plumes in San Diego coastal waters during rainstorm events. Remote Sens. Environ. 114, 332-344.

Li, G.X., Tang, Z.S., Yue, S.H., Zhuang, K.L., Wei, H.L., 2001. Sedimentation in the shear front off the YR mouth. Cont. Shelf Res. 21, 607-625.

Long, C.M., Pavelsky, T.M., 2013. Remote sensing of suspended sediment concentration and hydrologic connectivity in a complex wetland environment. Remote Sens. Environ. 129, 197-209.

Mao, X.Y., Jiang, W.S., Zhao, P., Gao, H.W., 2008. A 3-D numerical study of salinity variations in the Bohai Sea during the recent years. Cont. Shelf Res. 28, 2689-2699.

Molleri, G.S.F., Novo, E.M.L., de, M., Kampel, M., 2010. Space-time variability of the Amazon River plume based on satellite ocean color. Cont. Shelf Res. 30, 342-352.

Palacios, S.L., Peterson, T.D., Kudela, R.M., 2009. Development of synthetic salinity from remote sensing for the Columbia River plume. J. Geophys. Res. 114, http://dx.doi. org/10.1029/2008JC004895.

Park, E., Latrubesse, E.M., 2014. Modeling suspended sediment distribution patterns of the Amazon River using MODIS data. Remote Sens. Environ. 147, 232-242.

Petus, C., Marieu, V., Novoa, S., Chust, G., Bruneau, N., Froidefond, J.M., 2014. Monitoring spatio-temporal variability of the Adour River turbid plume (Bay of Biscay, France) with MODIS 250-m imagery. Cont. Shelf Res. 74, 35-49.

Qiao, S.Q., Shi, X.F., Zhu, A.M., Liu, Y.G., Bi, N.S., Fang, X.S., Yang, G., 2010. Distribution and transport of suspended sediments off the YR (Huanghe) mouth and the nearby Bohai Sea. Estuar., Coast. Shelf Sci. 86, 337-344.

Qing, S., Zhang, J., Cui, T.W., Bao, Y.H., 2013. Retrieval of sea surface salinity with MERIS and MODIS data in the Bohai Sea. Remote Sens. Environ. 136, 117-125.

Wang, H.J., Yang, Z.S., Bi, N.S., Li, H.D., 2005. Rapid shifts of the river plume pathway off the Huanghe (yellow) River mouth in response to water-sediment regulation scheme in 2005. Chin. Sci. Bull. 50 (24), 2878-2884.

Wang, H.J., Yang, Z.S., Saito, Y., Liu, J.P., Sun, X.X., 2006. Interannual and seasonal variation of the Huanghe (Yellow River) water discharge over the past 50 years: connections to impacts from ENSO events and dams. Glob. Planet. Change 50, 212-225.

Wang H.J. Wang A.M. Bi N.S. Zeng X.M. Xiao H.H. 2014. Seasonal distribution of suspended sediment in the Bohai Sea, China Cont. Shelf Res. 90 17-32

Wang, H.J., Yang, Z.S., Li, Y.H., Guo, Z.G., Sun, X.X., Wang, Y., 2007. Dispersion pattern of suspended sediment in the shear frontal zone off the Huanghe (YR) mouth. Cont. Shelf Res. 27, 854-871.

Wang, Q., Guo, X.Y., Takeoka, H., 2008. Seasonal variations of the Yellow River plume in the Bohai Sea: a model study. J. Geophys. Res. 113, C08046. http://dx.doi.org/10. 1029/2007JC004555.

Wang, Y.C., Liu, Z., Gao, H.W., Ju, L., Guo, X.Y., 2011. Response of salinity distribution around the YR mouth to abrupt changes in river discharge. Cont. Shelf Res. 31, 685-694.

Yu Y.G. Shi X.F. Wang H.J. Yue C.K. Chen S.L. Liu Y.G. Hu L.M. Qiao S.Q. 2013. Effects of dams on water and sediment delivery to the sea by the Huanghe (yellow River): the special role of water-sediment modulation Anthropocene 3 72-82

Zhang, J., Huang, W.W., Shi, M.C., 1990. Huanghe (YR) and its estuary: sediment origin, transport and deposition. J. Hydrol. 120, 203-223.

Zhao, P., Jiang, W.S., Mao, X.Y., Gao, H.W., Guo, X.Y., 2010. Salinity change and influencing factor in the Laizhou Bay from 2000-2005. Oceanol. Et. Limnol. Sin. 41, 12-23 (in Chinese, with English abstract). 